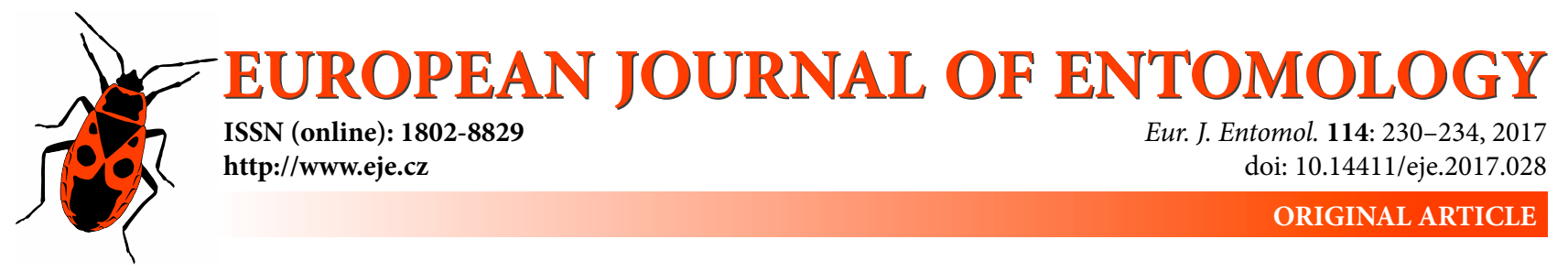

\title{
Acceptance of alien queens by the ruby ant Myrmica rubra (Hymenoptera: Formicidae): Gene flow by queen flow
}

\author{
JOUNI SORVARI ${ }^{1,2}$ \\ ${ }^{1}$ Department of Environmental and Biological Sciences, University of Eastern Finland, P.O. Box 1627, FI-70211 Kuopio, Finland; \\ e-mail: jouni.sorvari@uef.fi \\ ${ }^{2}$ Department of Biology, Section of Ecology, FI-20014 University of Turku, Finland
}

Key words. Hymenoptera, Formicidae, ants, Myrmica rubra, isolation by distance, polygyny, relatedness, social insects

\begin{abstract}
Social insect colonies, especially of ants, often include several egg-laying queens that are not always closely related to each other. At least in some cases, the ants seem to accept non-related queens into their colonies. Here I test whether the colony queen status (with or without a queen), genetic and geographic differences between source and recipient nests and the average relatedness of the workers in the recipient colony affect the acceptance of alien queens. I used field collected ruby ant Myrmica rubra colonies as a model system. Only the queen status significantly affected the acceptance process. Colonies without queens accepted alien queens more frequently than colonies with a queen. The nests without queens and nest fragments may act as vectors for gene flow by the movement of queens between nests, i.e., queen flow.
\end{abstract}

\section{INTRODUCTION}

Breeding groups can be divided into colonial and social forms. Colonial nesting groups typically consist of several breeding pairs that share the same neighbourhood and have no non-breeding helpers, e.g., many seabirds (Danchin \& Wagner, 1997). Social breeding groups are often family groups such as wolves where the helpers of the breeding pair are usually their own offspring (Mech \& Boitani, 2003). Social insects such as ants, social bees and wasps and termites are often termed eusocial since they have special morphologically distinct castes for different tasks, e.g., queens, males/drones, workers (Wilson, 1971). Often one queen and one or several male mates are the reproducers in a social insect colony. The term "colony" in social insect studies means the combination of reproducers and helpers. While in many cases, the reproduction of a social insect colony is based on a single queen and the sperm contribution of her male mate or mates, many social insect colonies permanently have several reproducing queens at the same time, a situation called polygyny (Wilson, 1971; Bourke \& Franks, 1995).

Among social insects, polygyny is especially common in ants, where over $40 \%$ of the species are classified as polygynous (Frumhoff \& Ward, 1992). Polygynous ant colonies are often family groups where daughters of the mother queen have been adopted back into the colony, but also non-nest mate queens are accepted by colonies of several species, especially those that are highly polygynous (e.g., Bourke \& Franks, 1995). Polygyny is problematic from the point of view of kin selection theory (individuals should favour kin in order to maximise their own genes in future generations; Hamilton, 1946), since by taking care and investing in unrelated offspring decreases the inclusive fitness of workers in such colonies. If the queen-pool consists of related queens, e.g., a mother and her daughters, the effect on the inclusive fitness of workers is positive due to increased productivity and colony survival. On the other hand, if a queen-pool consists of unrelated queens, the increase in productivity and colony survival should be more significant or of higher value. Increased productivity and colony survival can be valuable in a hostile environment, e.g., during colonization of new areas (Bourke \& Franks, 1995).

In the socially polymorphic ant Formica selysi Bondroit, which can have both single-queen and multiple-queen colonies, workers discriminate against non-nest mate queens (Meunier et al., 2011). All introduced newly mated foreign queens are killed, but young mated nest mate queens are frequently accepted. In another socially polymorphic ant, Formica exsecta Nylander, foreign queens are accepted as readily as nest mate queens, but their reproductive success is smaller, possibly due to workers favouring resident nest mate queens (Holzer et al., 2008a). In the socially monomorphic and always highly polygynous red wood ant Formica paralugubris Seifert mated non-nest mate queens are accepted as readily as nest mate queens (Holzer et al., 
2008b). Chernenko et al. (2012) report that in the black ant Formica fusca Linnaeus although almost $100 \%$ of introduced queens die, those introduced into colonies with a high relatedness, i.e., with few queens, are more likely to be dismembered, which indicates a violent death. This indicates that the level of polygyny may be significantly associated with the acceptance-rejection process, i.e., lowrelatedness colonies may accept unrelated queens more readily than the high-relatedness colonies.

Acceptance of alien queens may also happen when a colony lacks a queen. This can occur when a queen or queens in a colony die or if a nest is a queen less satellite nest of a colony with a queen. In the laboratory queen less colonies of the ruby ant Myrmica rubra (Linnaeus) accept alien conspecific queens (Brian, 1988; Elmes \& Brian, 1991). Large polygynous colonies of $M$. rubra can establish several satellite nests during summer, of which a high proportion, around 50\%, are queen less (Sorvari, unpubl.). Thus, satellite nests are potentially a system in which new queens are selected on the basis of their genetic and geographic distance and the worker-worker relatedness varies due to the number of queens in a colony or the subdivision of the original colony. Myrmica rubra is an invasive alien species in North America (Wetterer \& Radchenko, 2011; Naumann \& Higgins, 2015), where as in its native range it rapidly increases in abundance and spreads by means of multi-nest super colonies. Interestingly, this species seems to have an intraspecific parasite, a microgyne queen that does not contribute to worker production (Radchenko \& Elmes, 2010). The microgyne seems not to be closely related to the host colony (Vepsäläinen, et al., 2009; Schär \& Nash, 2014; Leppänen, et al., 2015), which raises the question whether this species allows alien conspecific queens to join its colonies.

The aim of this study was to address the following questions (1) do genetic and geographical distances affect the acceptance of new queens by the ruby ant Myrmica rubra, (2) do colonies with low genetic relatedness accept new queens easier than colonies with high genetic relatedness and (3) do queen less colonies accept queens easier than those with queens. To answer these questions a laboratory experiment was carried out.

\section{MATERIAL AND METHODS}

\section{Study populations and laboratory nests}

Nests of the ruby ant Myrmica rubra usually contain several breeding queens (polygyny) and typically consist of several nests (polydomy). The high degree of polygyny often causes a low degree of genetic relatedness among colony members (e.g., Seppä \& Walin, 1996). While a colony typically consists of several nests and the workers tolerate colony mates from different nests, alien conspecific workers are rejected aggressively (Radchenko \& Elmes, 2010). This species thrives in moist open or semi open areas like meadows and gardens. It is a native species in Eurasia but was accidentally introduced into North America and is now present locally in North-East and North-West USA and South-East and South-West Canada and known there as the European fire ant (Wetterer \& Radchenko, 2011; Naumann \& Higgins, 2015).
In this study, colonies (200-500 individuals per nest) of $M$. rubra were excavated in the field and brought to the laboratory. The colonies originated from five polydomous colonies (hereafter populations) spatially separated by $0.22-353 \mathrm{~km}$. Four of the colonies were located at Turku in South-West Finland $\left(60.454^{\circ} \mathrm{N}\right.$, $22.286^{\circ} \mathrm{E} ; 60.455^{\circ} \mathrm{N}, 22.283^{\circ} \mathrm{E} ; 60.459^{\circ} \mathrm{N}, 22.290^{\circ} \mathrm{E} ; 60.447^{\circ} \mathrm{N}$, $\left.22.220^{\circ} \mathrm{E}\right)$ and one at Viitasaari $\left(68.085^{\circ} \mathrm{N}, 25.854^{\circ} \mathrm{E}\right)$, Central Finland. From each population, seven nests were used in this study.

The workers, queens and offspring were carefully separated from the soil and 57 queens (of known origin) were isolated from the colonies. From this material, 32 colonies without and 25 with queens were established (total 57 colonies). The colonies were housed in test tubes with wet cotton wool. The tubes were individually placed in nest arenas, $15 \times 20 \mathrm{~cm}$ plastic boxes. To prevent the ants from escaping, the five $\mathrm{cm}$ high walls of the plastic boxes were treated with liquid Teflon (PTFE, fluon). Laboratory colonies with a queen consisted of a queen native to the colony, 50 workers and larvae. The colonies without queens were similar, but lacked a queen. The ants were fed ad libitum with a laboratory diet designed for ants (Bhatgar \& Whitcomb, 1970).

\section{Population genetics}

The molecular work was carried out by the Center of Evolutionary Applications (University of Turku, Finland). DNA was extracted using the salt extraction method of Aljanabi et al. (1997) with small modifications. Eight workers per nest were genotyped using seven markers divided between one multiplex (MP) and one single PCR. The multiplex consisted of the following markers: MS3.62, MS26, MS86 (Azuma, et al., 2005), Myrt-4 (Evans, et al., 1993), Msca50 (Henrich, et al., 2003) and Msca7 (Zeisset, et al., 2005). A single PCR for marker MP-67 (Herbers \& Mauser, 1998) was used. To improve the microsatellite peak profiles, a GTTT-tail was added to the 5' end of each non-labelled primer (Brownstein, et al., 1996).

Amplification was carried out in two $10-\mu 1$ reactions consisting of ca. $40 \mathrm{ng}$ of DNA, 0.1 to $0.3 \mu \mathrm{M}$ of each primer (one of which was fluorescently labelled) and $1 \mathrm{X}$ Qiagen multiplex PCR master mix (Qiagen Inc. Valencia, CA, USA). The single marker MP-67 also only amplified if the Qiagen's Q-solution was present during the reaction. The PCR profile followed manufacturer's standard protocol with the annealing temperatures of $57^{\circ} \mathrm{C}$ for the multiplex and $54^{\circ} \mathrm{C}$ for the single reaction. Amplifications were performed on PTC-100 (MJ Research) and AB 2720 (Applied Biosystems) thermal cyclers. For the electrophoresis the PCR products were pooled $(1.5 \mu 1$ of MP and $2 \mu 1$ of the single PCR) and diluted with $100 \mu \mathrm{l}$ of sterile water. $2 \mu \mathrm{l}$ of the pooled and diluted PCR product was combined with GS600LIZ size standard (Applied Biosystems) and HiDi-formamide (Applied Biosystems). Samples were denatured at $98^{\circ} \mathrm{C}$ for three minutes and the size of the fragments determined using capillary electrophoresis and an ABI PrismTM 3130xl genetic analysis instrument. The genotypes were scored using GENE MAPPER version 4.0 (Applied Biosystems) and following visual inspection, exported to a spreadsheet program for downstream analyses.

Pair wise population differentiation was measured as the $F_{S T}$ value. Pairwise $F_{S T}$ values were calculated using GENEPOP 4.0.10. Relatedness between nest mate workers was calculated using GenAlEx 6.5 macro in msExcel 2010 (Peakall \& Smouse, 2006, 2012). The relatedness ( $r$ ) was calculated using the Queller and Goodnight (1989) algorithm. The component caused by the positive inbreeding coefficient (F) was removed using Pamilo's correction (Pamilo, 1984, 1985) and this inbreeding corrected relatedness estimate $\left(r_{c}\right)$ for each colony was used in all analyses. 


\section{Queen acceptance trials and statistical analyses}

The isolated queens were kept separately for four days prior to the beginning of the trial. Similarly the colonies without queens were kept without queens for four days before the trial. In the trial an alien queen was introduced into the nest arena. The queen was classified as rejected if it was killed or treated/harassed aggressively outside the nest tube over a period of five days. The queen was classified as accepted if it was found alive inside the nest tube and treated amicably after five days. Nine colonies were presented with queens that originated from colonies at distances of 349-353 km from where the recipient colonies were collected and the other 48 nests were presented with queens collected from colonies at distances of $0.22-4.1 \mathrm{~km}$.

Statistical analyses were carried out using SAS 9.4 statistical software (SAS Institute Inc. Cary, NC, USA). Correlations were made using Pearson's correlation analysis. The analyses of queen acceptance were carried out using generalized linear models $($ GLM) with a binomial distribution $($ accepted $=1$, rejected $=0$ ) and logit link function in the procedure GLIMMIX (SAS Institute Inc. 2008). Backward elimination was used to test the models.

\section{RESULTS}

Of the 32 foreign queens 29 (91\%) were accepted by the colonies without queens whereas only 8 out of $25(32 \%)$ were accepted by colonies with queens. However, additional analyses were carried out to determine whether there are other predictors for queen acceptance.

There seemed to be no isolation by distance among populations, because there was no significant correlation between geographic distance and the degree of genetic differentiation, $F_{S T}(r=-0.22, \mathrm{p}=0.54)$. There was one population (Patterihaka), which was genetically more different $\left(F_{S T}\right)$ to its close neighbours than the geographically most disjunct population (Viitasaari; Table 1). The Patterihaka population seems to have undergone a genetic bottleneck or more likely a founder effect. It does not have a positive inbreeding coefficients but the effective number of alleles and allelic diversity are the lowest among the populations compared (see Table 2). When the Patterihaka population was removed from the analysis the correlation between genetic differentiation and geographic distance remained non-significant $(r=0.51, \mathrm{p}=0.30)$.

The average nest mate worker relatedness estimates $\left(r_{c}\right)$ varied between -0.09 and 0.71 (mean \pm SD: $0.28 \pm 0.23$ ). This is within the range of zero -0.82 recorded earlier by Seppä and Walin (1996). Again, the Patterihaka population differed from the others; the population mean $r_{c}$ was 0.61

Table 1. Pairwise genetic $\left(F_{S T}\right)$ and geographic distances $(\mathrm{km})$ between populations. $F_{S T}$ value is in bold. UTU1 - University of Turku campus 1, UTU2 - University of Turku campus 2. Notice the high $F_{S T}$ values between the Patterihaka population and all others.

\begin{tabular}{lcccc}
\hline Population & Patterihaka & Viitasaari & UTU1 & UTU2 \\
\hline \multirow{2}{*}{ Viitasaari } & $\mathbf{0 . 2 6 7 2}$ & & & \\
& 353.0 & & & \\
\multirow{2}{*}{ UTU1 } & $\mathbf{0 . 2 6 3 9}$ & $\mathbf{0 . 0 9 8 5}$ & & \\
& 3.62 & 349.9 & & \\
\multirow{2}{*}{ UTU2 } & $\mathbf{0 . 2 6 9 6}$ & $\mathbf{0 . 0 8 2 1}$ & $\mathbf{0 . 0 6 5 8}$ & \\
& 3.7 & 350.2 & 0.22 & \\
\multirow{2}{*}{ Nummi } & $\mathbf{0 . 3 4 5 2}$ & $\mathbf{0 . 0 8 8 0}$ & $\mathbf{0 . 0 5 4 9}$ & $\mathbf{0 . 0 9 8 5}$ \\
& 4.07 & 349.8 & 0.51 & 0.59 \\
\hline
\end{tabular}

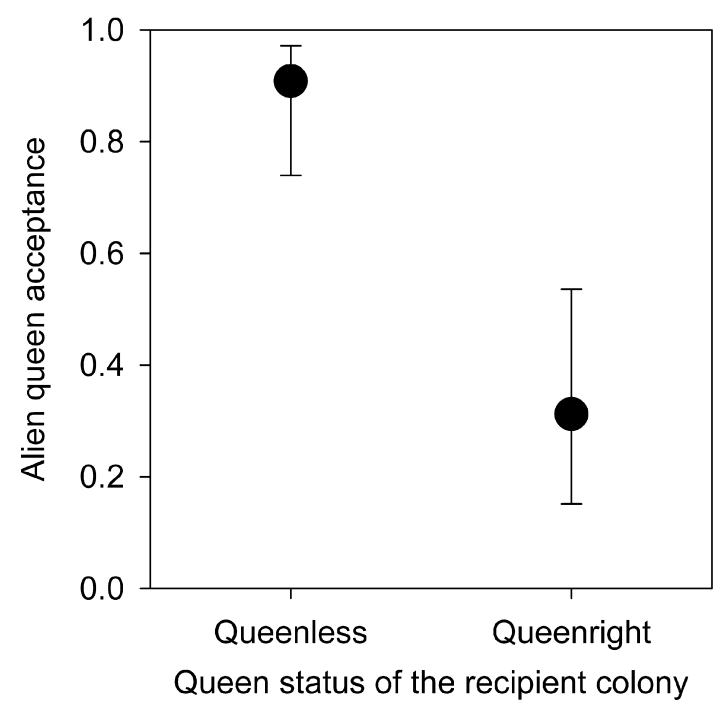

Fig. 1. Relationship between queen status and proportion of colonies that accepted conspecific queens. Estimated marginal means and $95 \%$ confidence limits of a model in which queen status is the only explanatory factor $\left(F_{1,55}=16.62, p=0.0001\right)$.

$( \pm$ SD 0.1$)$ and ranged between $0.47-0.71$, while in all the other populations studied the nest mean $r_{c}$ ranged between $0.12-0.23$ (see Table 2). Of the seven Patterihaka colonies, seven lacked queens and six colonies with queens were established before the trials. Thus, in the following queen acceptance trials the 13 artificial Patterihaka nests had considerably higher relatedness estimates than the rest of the 44 artificial colonies.

The $F_{S T}$ between source and recipient populations and the average degree of relatedness among recipient colony workers was significantly positively correlated $(r=0.69$, $\mathrm{p}<0.0001$ ), and since correlated variables cannot be used as explanatory variables in the same model, two different models were run. Model set 1 included queen status (with or without a queen), relatedness and geographic distance and the model set 2 otherwise similar but the relatedness variable was replaced by the $F_{S T}$ value.

In both model sets all possible interactions between class variable queen status and continuous variables (relatedness, $F_{S T}$, geographic distance) were non-significant (Table 3 ) and in both of the model sets only queen status (with or without a queen) significantly affected queen acceptance (Table 3; Fig 1).

The populations did not differ in the percentage that accepted queens but the queen status (with or without a

Table 2. The genetic structure of the five populations studied using seven microsatellite markers. Population means for nest values for the number of alleles $(\mathrm{Na})$, number of effective alleles $(\mathrm{Ne})$, Shannon index for genetic diversity $(S h l)$, inbreeding coefficient $\left(F_{I S}\right)$ and inbreeding corrected average nest mate worker relatedness $\left(r_{c}\right)$. Means are presented with \pm SE except $F_{\text {IS }}$ and $r_{c}$ with $\pm S D$.

\begin{tabular}{lccccc}
\hline Population & $\mathrm{Na}$ & $\mathrm{Ne}$ & $\mathrm{Shl}$ & $F_{\text {IS }}$ & $r_{c}$ \\
\hline Viitasaari & $4.29 \pm 1.09$ & $2.71 \pm 0.74$ & $0.96 \pm 0.22$ & $-0.12 \pm 0.24$ & $0.22 \pm 0.31$ \\
UTU1 & $3.00 \pm 0.58$ & $2.08 \pm 0.31$ & $0.74 \pm 0.17$ & $-0.10 \pm 0.07$ & $0.12 \pm 0.15$ \\
UTU2 & $2.71 \pm 0.52$ & $2.02 \pm 0.33$ & $0.73 \pm 0.17$ & $-0.01 \pm 0.14$ & $0.21 \pm 0.12$ \\
Patterihaka & $1.86 \pm 0.14$ & $1.65 \pm 0.11$ & $0.53 \pm 0.09$ & $-0.22 \pm 0.10$ & $0.61 \pm 0.10$ \\
Nummi & $3.00 \pm 0.72$ & $2.08 \pm 0.39$ & $0.72 \pm 0.18$ & $-0.11 \pm 0.10$ & $0.23 \pm 0.06$ \\
\hline
\end{tabular}


Table 3. Results of the generalized linear models (GLM $\left.M_{\text {INOMiL }}\right)$. Two different model sets were used because of the correlation between $F_{S T}$ and nest mate worker relatedness. The models were run using the backward elimination method, i.e., the least significant interaction term was removed first and the model was re-run until only fixed variables remained.

\begin{tabular}{lccc}
\hline & DF & $\mathrm{F}$ & $\mathrm{p}$ \\
\hline \multicolumn{1}{c}{ Model set 1 } & & & \\
Queen status $\times$ nest mate worker relatedness & 1,51 & 1.27 & 0.27 \\
Queen status $\times$ geographic distance & 1,52 & 1.98 & 0.16 \\
Nest mate worker relatedness & $1,31.22$ & 1.60 & 0.22 \\
Geographic distance & 1,53 & 1.72 & 0.20 \\
Queen status & 1,53 & 15.61 & $\mathbf{0 . 0 0 0 2}$ \\
\hline Model set 2 & & & \\
Queen status $\times F_{S T}$ & 1,51 & 0.54 & 0.47 \\
Queen status $\times$ geographic distance & 1,52 & 1.56 & 0.22 \\
$F_{\text {ST }}$ & $1,29.62$ & 0.81 & 0.38 \\
Geographic distance & 1,53 & 2.11 & 0.15 \\
Queen status & 1,53 & 15.43 & $\mathbf{0 . 0 0 0 2}$ \\
\hline
\end{tabular}

queen) did (populations $F_{4,36.12}=1.72, \mathrm{p}=0.17$; queen status $\left.F_{1,51}=12.95, \mathrm{p}=0.0007\right)$. Because the Patterihaka population was genetically different from the others, the percentage acceptance by Patterihaka nests differed from that of nests from other locations. Despite the difference in population structure the acceptance of alien queens by Patterihaka nests was the similar than that of nests from other locations $\left(F_{1,38.02}=0.68, \mathrm{p}=0.41\right)$.

\section{DISCUSSION}

Clearly, the status of the recipient colony, whether it is has a queen or not, is critical in determining whether foreign queens are accepted. The previous finding of Brian (1988), and Elmes \& Brian (1991) are strongly supported by the current data. However, it is worth noting that in the current work $32 \%$ of the colonies with queens also accepted alien queens. A $68 \%$ risk of being killed may still be smaller than the risk of a queen failing to found a nest.

The effects of geographic and genetic distances and the relatedness structure of nests were not examined in the earlier studies on this species (Brian, 1988; Elmes \& Brian, 1991). Here their effects were analyzed and their clearly non-significant role was somewhat surprising. In the black ant Formica fusca, introduced alien queens were violently killed in nests that had a high degree of nest mate relatedness (Chernenko et al., 2012). In the present study percentage queen acceptance was not affected by the degree of relatedness among nest mate workers. Workers may be unable to distinguish between alien and related queens or there is no strong selection against unrelated queens. This could be because the acceptance of unrelated queens is beneficial since it helps maintain genetic diversity by enhancing gene flow between distant nest groups (or colonies).

In an earlier study, M. rubra readily established satellite nests in covered tubes placed one metre from natural nests (Sorvari, unpubl.). These nests contained workers, larvae and pupae, but in most cases no queens. This happened simultaneously at different locations and may indicate that similar satellite nests are common in M. rubra in nature. In summer satellite nests without queens may have an impor- tant role in securing gene flow by providing a safe-haven outside the nest group for migrant queens. Possibly most of the gene-flow in ants happens when a local queen (gyne) mates with a dispersing male. However, gene-flow by migrant queens may also exist. This kind of gene-flow in ants could well be called queen-flow.

Myrmica rubra is by no means the only species using queen-flow as non-nest mate queens are accepted by many polygynous species, like red wood ants Formica polyctena Förster (Yamauchi \& Czechowski, 1994), Formica paralugubris (Holzer et al., 2008) and the narrow headed ant Formica exsecta (Holzer et al., 2008a). In the black ant Formica fusca alien queens are also accepted or tolerated, but workers neglect their maintenance, which results in the death of the tolerated alien queens (Chernenko et al., 2012). Formica fusca is only moderately polygynous, i.e. there are only a few queens in a colony (Sundström et al., 2005) and it remains unanswered whether the survival of alien queens is higher in highly polygynous species like the polygynous red wood ants, or Myrmica rubra or other highly polygynous ant species.

The genetically distinct population (Patterihaka) may well have been established recently. This is supported by its low allelic richness, which could explain its high degree of nest mate relatedness. However, the high nest mate relatedness could be a result of mother-daughter queen pools in a founder population nest. The pattern in the relatedness for that population could also indicate multicolonial polygyny with few queens per nest (Huszár et al., 2014). The nests in that population were populous, in a line along the edge of a forest with distance between neighbouring nests less than $1 \mathrm{~m}$. Myrmica rubra is very aggressive against alien conspecific workers, and thus, such a multicolonial population would be unstable and would eventually turn into a unicolonial population (Huszár et al., 2014) or a wider dispersion of the independent nests.

Myrmica rubra is a serious invasive species in North America. The tendency of M. rubra to accept alien queens may be one of the factors behind its invasion success, because it increases the survival of colonies and increases the gene pool (e.g., Huszár et al., 2014). In addition, accidentally translocated parts of colonies without queens may readily accept alien conspecific queens, which makes colonisation of new areas more successful and rapid. However, participation of queens in nuptial flights is rarely seen in North America, and establishment of new colonies may rely mainly on colony budding (Hicks, 2012). In addition, solitary queens have seen wandering at distances greater than $10 \mathrm{~m}$ from nearest nests in spring both in the introduced and native ranges (pers. observ. by R.J. Higgins and the author, respectively).

On the other hand the high percentage acceptance of non-related queens by ants could lead to intraspecific parasitism where alien queens may concentrate on producing their own sexual offspring and leaving the production of workers to the original queens. This seems to already have happened in Myrmica rubra as it has an interspecific parasite or "semi-parasite", a microgyne, called "microrubra" 
(Vepsäläinen et al., 2009; Radchenko \& Elmes, 2010; Schar \& Nash, 2014; Leppänen et al., 2015). On the one hand the opposite behaviour has also been suggested. In that case, alien queens are accepted but they are forced to produce only workers, for example by killing the male offspring of alien queens and by rearing female offspring of alien queens on a poor nutrition so that they develop into workers (Holzer et al., 2008a).

To conclude, joining individuals from different populations can be beneficial in terms of gene-flow. Social groups may accept non reproductive helpers in order to enhance the breeding success of the breeding individuals, but it does not improve the gene-pool of the group or population. On the other hand, by accepting reproductive individuals a positive gene flow is maintained. In ants like M. rubra, alien non reproductive helpers - workers - are typically rejected whereas a high percentage of alien breeding individuals, queens, are accepted. It is possible, yet still speculative, that temporally nests without queens may play a role in the gene-flow - queen-flow process.

ACKNOWLEDGEMENTS. M.-K. Haatanen and S.-R. Vesterlund (University of Turku) helped in the maintenance of laboratory colonies. D. Blande provided comments on the structure and English of this manuscript. R.J. Higgins and anonymous reviewers provided constructive comments on the manuscript. The study was funded by the Emil Aaltonen Foundation.

\section{REFERENCES}

Aljanabi S.M. \& Martinez I. 1997: Universal and rapid saltextraction of high quality genomic DNA for PCR-based techniques. - Nucl. Acids Res. 25: 4692-4693.

Azuma N., Takahashi J., Kikuchi T., Yoshimura M., Onoyama K. \& HigASHI S. 2005: Microsatellite loci for Myrmica kotokui and their application in some congeneric ant species distributed in northern Japan. - Mol. Ecol. Notes 5: 118-120.

BhatKar A.P. \& Whitcomb W.H. 1970: Artificial diet for rearing various species of ants. - Fla Entomol. 53: 229-232.

Bourke A.F.G. \& Franks N.R. 1995: Social Evolution in Ants. Princeton University Press, Princeton, $550 \mathrm{pp}$.

BRIAN M.V. 1988: Queen selection by worker groups of the ant Myrmica rubra L. - Anim. Behav. 36: 914-925.

Chernenko A., Helanterä H. \& Sundström L. 2012: Colony kin structure and recruitment in the ant Formica fusca (Hymenoptera: Formicidae). - Myrmecol. News 16: 93-100.

DANCHIN E. \& WAGNER R.H. 1997: The evolution of coloniality: the emergence of new perspectives. - Trends Ecol. Evol. 12: 342-347.

Elmes G.W. \& BRIAn M.V. 1991: The importance of the egg-mass to the activity of normal queens and microgynes of Myrmica rubra L. (Hym. Formicidae). - Insectes Soc. 38: 51-62.

Evans J.D. 1993: Parentage analyses in ant colonies using simple sequence repeat loci. — Mol. Ecol. 2: 393-397.

FRUMHOFF P.C. \& WARD P.S. 1992: Individual-level selection, colony-level selection, and the association between polygyny and worker monomorphism in ants. - Am. Nat. 138: 559-590.

Hamilton W.D. 1946: The genetical evolution of social behaviour. - J. Theor. Biol. 7: 1-16.

Heinrich K., Sander A., Wolters V. \& Dauber J. 2003: Isolation and characterization of microsatellite loci in the ant Myrmica scabrinodis. - Mol. Ecol. Notes 3: 304-306.
Herbers J.M. \& Mouser R.L. 1998: Microsatellite DNA markers reveal details of social structure in forest ants. - Mol. Ecol. 7: 299-306.

Hicks B.J. 2012: How does Myrmica rubra (Hymenoptera: Formicidae) disperse in its invasive range? Record of male-only swarming flights from Newfoundland. - Myrmecol. News 16: $31-34$.

Holzer B., Chapuisat M. \& Keller L. 2008a: Foreign ant queens are accepted but produce fewer offspring. - Behav. Ecol. 157: 717-723.

Holzer B., Meunier J., Keller L. \& Chapuisat M. 2008b: Stay or drift? Queen acceptance in the ant Formica paralugubris. Insectes Soc. 55: 392-396.

Huszár D.B., Larsen R.S., Carlsen S., Boomsma J.J. \& Pedersen J.S. 2014: Convergent development of ecological, genetic, and morphological traits in native supercolonies of the red ant Myrmica rubra. - Behav. Ecol. Sociobiol. 68: 1859-1870.

Leppänen J., Seppä P., VepsäläInen K. \& Savolainen R. 2015: Genetic divergence between the sympatric queen morphs of the ant Myrmica rubra. - Mol. Ecol. 24: 2463-2476.

Mech L.D. \& Boitani L. 2003: Wolves: Behaviour, Ecology and Conservation. University of Chicago Press, Chicago, 472 pp.

Meunier J., Reber A. \& Chapuisat M. 2011: Queen acceptance in a socially polymorphic ant. - Anim. Behav. 81: 163-168.

Naumann K. \& Higgins R.J. 2015: The European fire ant (Hymenoptera: Formicidae) as an invasive species: impact on local ant species and other epigaeic arthropods. - Can. Entomol. 147: 592-601.

Peakall R. \& Smouse P.E. 2006: GENALEX 6: Genetic analysis in Excel. Population genetic software for teaching and research. — Mol. Ecol. Notes 6: 288-295.

Peakall R. \& Smouse P.E. 2012: GenAlEx 6.5: Genetic analysis in Excel. Population genetic software for teaching and research - an update. - Bioinformatics 28: 2537-2539.

Radchenko A.G. \& Elmes G.W. 2010: Myrmica Ants Hymenoptera: Formicidae of the Old World. Vol. 3. Natura Optima Dux Foundation, Warsaw, $791 \mathrm{pp}$.

SAS Institute Inc. 2008: SAS/STAT® 9.2 User's Guide. SAS Institute Inc, Cary, NC.

SCHÄr S. \& NASH D.R. 2014: Evidence that microgynes of Myrmica rubra ants are social parasites that attack old host colonies. - J. Evol. Biol. 27: 2396-2407.

SEPpä P. \& Walin L. 1996: Sociogenetic organization of the red ant Myrmica rubra. - Behav. Ecol. Sociobiol. 38: 207-217.

Sundström L., Seppë P. \& PAmilo P. 2005: Genetic population structure and dispersal patterns in Formica ants - a review. Ann. Zool. Fenn. 42: 163-175.

Vepsäläinen K., EbSen J.R., SAVOlainen R. \& Boomsma J.J. 2009: Genetic differentiation between the ant Myrmica rubra and its microgynous social parasite. - Insectes Soc. 56: 425-437.

Wetterer J.K. \& Radchenko A.G. 2011: Worldwide spread of the ruby ant, Myrmica rubra (Hymenoptera: Formicidae). Myrmecol. News 14: 87-96.

WiLson E.O. 1971: The Insect Societies. The Belknap Press of Harvard University Press, Cambridge, MA, 548 pp.

Zeisset I., Ebsen J.R. \& Boomsma J.J. 2005: Dinucleotide microsatellite DNA loci from the ant Myrmica scabrinodis. - Mol. Ecol. Notes 5: 163-164.

Received November 28, 2016; revised and accepted March 27, 2017 Published online April 18, 2017 